\section{Outflow and inflow in movement duplication}

\author{
BILL JONES \\ University of Queensland, St. Lucia, Queensland, Australia 4067
}

Thirty Ss were assigned randomly to one of three conditions of blindfolded movement duplication: (1) constrained active movement (the $E$ determined the end point of the S's movement), (2) unconstrained active movement, and (3) passive movement. Ss' absolute accuracy of duplication of the three conditions was compared. Significant differences were observed between the three conditions, though there was no significant difference between Conditions 1 and 3. The results are discussed in terms of "outflow" and "inflow" models of kinesthesis, and it is argued that some support is given to the outflow model.

Despite emphasis by many theorists (e.g., Bahrick, 1957; Gibbs, 1954, 1965; Annett, 1971) on the role of proprioception in human performance, there have been few studies of Ss' ability to reproduce movements without visual guidance. Howard and Templeton (1966) could list only two studies dealing with the duplication of extent of movement without vision: Woodw orth (1899) and Hollingworth (1909).

In general, theorists have taken for granted the role of proprioceptive feedback signals in skilled performance and have ignored the alternative theory that in the absence of visual (or other exteroceptive) guidance, the central nervous system (CNS) may have knowledge of active movement by monitoring its own efferent signals (this latter theory will be referred to here as "the efferent outflow theory," outflow for short, and is contrasted with the feedback or "proprioceptive inflow theory," inflow for short). Since inflow theories need to assume central monitoring of efferent signals to give a "template" against which proprioceptive signals may be compared (e.g., von Holst, 1954) and since studies with spinally deafferented animals (reviewed by Taub \& Berman, 1968) have shown that proprioceptive signals are not a necessary condition for movement learning, the outflow theory is, in fact, the more parsimonious account.

The aim of the present experiment was to provide some evidence of the importance of outflow vs inflow in the duplication of movements. For the perception of movement to be served by outflow, the $S$ would need to know the goal of his movement in advance. The ability of Ss to duplicate unconstrained voluntary arm movements and passive movements of the same limb was compared to their ability to duplicate their arm movements when they had no knowledge at the beginning of the movement of its end point. This "constrained movement" shares characteristics of both active and passive movement-active in that it is the $\mathbf{S}$ himself who moves and passive in that the $\mathbf{S}$ can make no decision either in advance or during the course of the movement about where he will finish. The hypothesis was that unconstrained active movements are duplicated with greater accuracy than both passive and constrained active movements. If constrained active movements were duplicated only with the accuracy of passive movements, we should have evidence for the role of central monitoring of efference signals in that absence of "preset" control leads to deterioration in duplication of active movement.

\section{METHOD \\ Subjects}

Thirty university undergraduates served as Ss. Ten were assigned randomly to each of three experimental procedures.

\section{Apparatus}

A thimble was mounted on a rail and could be slid along it by the $S$ or the E. A pointer attached to the thimble moved along a scale below the slide and enabled the $E$ to read off the distance which the slide had moved.

\section{Procedure}

Condition 1: Constrained active movement. The $\mathrm{S}$, with his index finger in the thimble, moved it along the rail as quickly as possible until he came to a stop set by the $\mathrm{E}$. He then moved back to the starting point and tried to reproduce as accurately as possible his previous movement, the $\mathrm{E}$ meanwhile having removed the stop.

Condition 2: Unconstrained active movement. The $\mathrm{S}$ placed his index finger in the thimble and moved it along the rail as quickly as possible to whatever position he preferred. He then moved back to the beginning and attempted to duplicate the first movement.

Condition 3: Passive movement. The $S$ placed his index finger in the thimble and the $E$ moved the thimble as quickly as possible to a predetermined position, then moved it back to the starting point. The $S$ then tried to duplicate the passive movement, as in Conditions 1 and 2.

Under all procedures, Ss were blindfolded so that they could not view their movements. Under Conditions 1 and 3 , there were 50 trials using distances of $10,15,20,25$, and $30 \mathrm{~cm}, 10$ times over in a random order. There were similarly 50 trials per S under Procedure 2. Ss' absolute error on each trial was recorded in millimeters.

\section{RESULTS}

Contrary to Posner (1967), no evidence of a correlation between extent of standard and accuracy of reproduction could be found, and data have been combined irrespective of the length of the standard for all three conditions. The difference between this finding and that of Posner may be due to the fact that I studied movements to the side of the body, whereas Posner studie;movements in front of the body. Mean absolute error scores and standard deviations for the three conditions are given in Table 1. Absolute error scores here are, in fact, equivalent to underestimation scores, since no $S$ in any condition showed any tendency to overestimate, unlike the studies of Paillard and Brouchon (1968), who found some tendency to overestimate in passive conditions.

Since it cannot be assumed that the range of active movements had a normal distribution, the data were analyzed by means of the nonparametric Kruskal-Wallis one-way analysis of variance (Siegel, 1956), which indicated significant differences between conditions $(\mathrm{H}=\mathbf{2 0 . 8 9}, \mathrm{df}=2$, $\mathrm{p}<.001)$. When Conditions 1 and 3 were compared by means of a t test, there was no significant difference $(t=0.11, d f=18)$. In other words, constrained active movements are apparently indistinguishable from passive movements in the present experiment.

Though unconstrained active movement is more accurate than either of the other two conditions, this may have been because $S s$ in this condition used a smaller and less variable range of movements. However, every $S$ in Condition 2 selected a range of movements greater than $20 \mathrm{~cm}$, the range of the standards in the other two conditions. The smallest range chosen

Table 1

Mean Absolute Error and Standard Deviation in Centimeters for the Three Matching Conditions

Condition 1 Condition 2 Condition 3 $\begin{array}{llllll}M & \text { SD } & M & \text { SD } & M & \text { SD }\end{array}$

$\begin{array}{llllll}2.03 & 1.78 & 0.88 & 0.85 & 2.15 & 2.13\end{array}$ 
Table 2

Relationship Between Accuracy and Standard Settings in Centimeters for Ss in Condition 2

\begin{tabular}{rcrr}
\hline & \multirow{2}{*}{$\begin{array}{c}\text { Mean } \\
\text { S }\end{array}$} & \multicolumn{2}{c}{ Settings } \\
\cline { 4 - 4 } $\mathbf{A c c u r a c y}$ & $\mathrm{M}$ & \multicolumn{1}{c}{ SD } \\
\hline $\mathbf{2}$ & $\mathbf{9 4}$ & $\mathbf{2 5 . 8 4}$ & $\mathbf{1 7 . 5 2}$ \\
$\mathbf{3}$ & 96 & $\mathbf{3 3 . 1 2}$ & $\mathbf{7 . 0 9}$ \\
$\mathbf{4}$ & $\mathbf{8 4}$ & $\mathbf{3 8 . 4 3}$ & $\mathbf{1 4 . 8 7}$ \\
$\mathbf{5}$ & $\mathbf{8 6}$ & $\mathbf{3 7 . 9 1}$ & $\mathbf{1 1 . 7 4}$ \\
$\mathbf{6}$ & $\mathbf{8 7}$ & $\mathbf{2 6 . 2 8}$ & $\mathbf{5 . 0 4}$ \\
$\mathbf{7}$ & $\mathbf{8 9}$ & $\mathbf{3 0 . 1 8}$ & $\mathbf{1 1 . 3 3}$ \\
$\mathbf{8}$ & $\mathbf{8 0}$ & $\mathbf{3 4 . 3 7}$ & $\mathbf{1 0 . 3 0}$ \\
$\mathbf{9}$ & $\mathbf{8 5}$ & $\mathbf{3 2 . 6 9}$ & $\mathbf{1 6 . 6 5}$ \\
$\mathbf{1 0}$ & $\mathbf{8 6}$ & $\mathbf{3 8 . 4 3}$ & $\mathbf{9 . 2 4}$ \\
\hline
\end{tabular}

was $35 \mathrm{~cm}(20-55 \mathrm{~cm})$ and the overall range was $62.5(5-67.5 \mathrm{~cm})$ as compared with $20 \mathrm{~cm}$ for the other two conditions. Table 2 shows means and standard deviations for standard settings against mean accuracy for all Ss in Condition 2. There is no clear relationship between standard settings and accuracy, and it is obvious that every $\mathbf{S}$ made mean standard settings in excess of the mean of $20 \mathrm{~cm}$ in the other two conditions; only two Ss had standard settings which were less variable than settings in Conditions 1 and 3 , where the standard deviation was 7.07 .

\section{DISCUSSION}

Though Ss were instructed to move as quickly as possible, there may have been differences between groups in patterns of acceleration and deceleration. Characteristically, Ss decelerate near target position (Annett, Golby, \& Kay, 1958). Without a known target position, Ss' movements in Condition 1 are unlikely to have shown a decelerating phase. Thus there is a possibility, which I would like to leave open, that possible differences between conditions in this respect may have influenced the present results.

At least two hypotheses could account for the greater accuracy of movement duplication of Condition 2 . Duplication of movement here could be based on outflow plus inflow with proprioceptive signals serving to stamp in the centrally monitored efferent copy. Alternatively, proprioceptive signals might be no more than registration of muscular effort (Merton, 1964) without information as to direction or extent of movement. Duplication of movement would consequently be mediated by outflow alone.

Since the outflow plus inflow account is frequently assumed, it may be in order to speculate that central monitoring of efference can by itself mediate knowledge of active movement. There is considerable evidence that, following passive stretch of muscle, only the joint receptors can calibrate accurately changes in direction and extent of movement (Boyd \& Roberts, 1953; Skoglund, 1956; Rose \& Mountcastle, 1959; Burgess \& Clark, 1969). Anesthetization of the joint capsule abolishes the perception of passive movement but leaves the ability to perceive and duplicate voluntary movement unimpaired (Browne, Lee, \& Ring, 1954). Consequently, we know that joint receptors rather than muscle spindles are implicated in passive movement, but joint receptor firing is not necessary in voluntary movement. Since the muscle spindle does not signal changes in direction or extent of movement during passive stretch (Rose \& Mountcastle, 1959), the \& parsimonious assumption is that the proprioceptors are not concerned in supplying feedback signals during active stretch and that, instead, monitoring of its own efference provides the CNS with sufficient data for control of movement.

To save the inflow theory, we would need to assume, as do Paillard and Brouchon (1968), that the muscle spindle is tied in with active movement (they do not explain why the pattern of firing by the spindle should be different for voluntary and passive movement). Since there is no reason to think that the behavior of the muscle spindle differs in the constrained and unconstrained conditions, the present paradigm provides a crucial test between the Paillard and Brouchon hypothesis and the outflow theory. If the joint capsule is blocked by anesthetic, and constrained active movement still differs significantly from unconstrained and passive movements as here, the Paillard and Brouchon hypothesis would be refuted.

\section{REFERENCES}

ANNETT, J. Acquisition of skill. British Medical Bulletin, 1971, 27, 266-271.
ANNETT, J., GOLBY, C. W., \& KAY, H. The measurements of elements in an assembly task-the information output of the human motor system. Quarterly Journal of Experimental Psychology, $1958,10,1.11$.

BAHRICK, H. An analysis of the stimulus variables influencing the proprioceptive control of movements. Psychological Control of movements.

BOYD, I. A., \& ROBERTS, T. D. M. Proprioceptive discharge endings in the knee joint of the cat. Journal of Physiology, 1953, 122, 38-59.

BRINDLEY, G. S., \& MERTON, P. A. The absence of position sense in the human eye. Journal of Physiology, 1960, 153, 127.

BROWNE, K., LEE, J., \& RING, P. A. The sensation of passive movement at the metatarso-phalangeal joint of the great toe in man. Journal of Physiology, 1964, $126,448-458$.

BURGESS, P. R., \& CLARK, F. J. Characteristics of knee joint receptors in the cat. Journal of Physiology, 1969, 203, 317-335.

GIBBS, C. B. The continuous regulation of skilled response by kinaesthetic feedback. British Journal of Psychology, 1954, 45, 24-39

GIBBS, C. B. Probability learning in step-input tracking. British Joumal of Psychology, 1965, 56, 233-242.

HOLLINGWORTH, H. L. The inaccuracy of movement. Archives of Psychology, New York, 1909, 2, 187.

HOLST, E. von. Relations between the central nervous system and peripheral organs. British Journal of Animal Behaviour, 1954, 3, 89-94.

HOWARD, I. P., \& TEMPLETON, W. B. Human spatial orientation. New York: Wiley, 1966.

MERTON, P. A. Human position sense and sense of effort. Symposia of the Society for Experimental Biology, 1964, 18, $387-400$.

PAILLARD, J., \& BROUCHON, M. Active and passive movements in the calibration of the position sense. In S. J. Freedman (Ed.), The neuropsychology of spatially oriented behavior. Homewood. III: Dorsey Press, 1968.

POSNER, M. I. Characteristics of visual and kinesthetic memory codes. Journal of Experimental Psychology, 1967, 75, 103-107.

ROSE, J. E., MOUNTCASTLE, V. B. Touch and kinesthesis. In J. Field (Ed.), Handbook of physiology. Section I: Neurophysiology. Vol. 1. American Physiological Society, 1959.

SIEGEL, S. Nonparametric statistics for the behavioral sciences. New York: McGraw-Hill, 1956 .

SKOGLUND, S. Anatomical and physiological studies of knee-joint innervation in the cat. Acta Phy siologica Scandinavia, 1956, 36 (Suppl. 124).

TAUB, E, \& BERMAN, A.J. Movement and learning in the absence of sensory feedback. In S. J. Freedman (Ed.), The neuropsychology of spatially oriented behavior. Homewood, Ill: Dorsey Press, 1968.

WOODWORTH, R. S. The accuracy of voluntary movement. Psychological Review, 1899, 3 (Monograph Suppl. 3).

(Accepted for publication February 18, 1972.) 